\section{IN BRIEFS}

\section{RHEUMATOID ARTHRITIS}

Serum C-terminal cross-linking telopeptide of type I collagen (ICTP) is a marker of type I collagen degradation. Patients with early rheumatoid arthritis $(n=182)$ were assessed to ascertain whether serum ICTP could predict progression of joint destruction detected by X-ray. Hakala et al. concluded that measurement of serum ICTP levels after 6 months of combination drug therapy might help physicians decide whether their patients' treatment regimens should be intensified.

Original article Hakala M et al. (2008) Combination drug strategy in recent-onset rheumatoid arthritis suppresses collagen I degradation and is associated with retardation of radiological progression. Scand J Rheumatol 37: 90-93

Biomarkers for rheumatoid arthritis have not yet been identified. Serum samples from patients with rheumatoid arthritis $(n=90)$, patients with ankylosing spondylitis $(n=30)$ and healthy individuals $(n=36)$ were recently analyzed by SELDI-TOF MS (surfaceenhanced laser desorption/ionization timeof-flight mass spectrometry) to determine whether biomarker patterns could be identified for each group. This method identified biomarker patterns with good sensitivity and specificity for each condition, suggesting that SELDI-TOF MS might be a useful tool for biomarker discovery and for molecular diagnosis.

Original article Liu W et al. (2008) Using SELDI-TOF MS to identify serum biomarkers of rheumatoid arthritis. Scand J Rheumatol 37: 94-102

The safety of oral tacrolimus therapy for rheumatoid arthritis was analyzed in a retrospective study of 42 patients. The most common adverse effects were gastrointestinal symptoms (noted in $45.2 \%$ of patients), which presented early in the treatment regimen and were dose-dependent. Although these symptoms were not severe, half of the patients discontinued treatment as a result of these undesirable effects. Infections and hyperglycemia were also reported.

Original article Akimoto K et al. (2008) Safety profile of tacrolimus in patients with rheumatoid arthritis. Clin Rheumatol [doi: 10.1007/s10067-008-0931-z]

\section{SYSTEMIC SCLEROSIS}

The effects of a treatment regimen consisting of 6 months of intravenous cyclophosphamide $\left(0.6 \mathrm{~g} / \mathrm{m}^{2}\right.$ per month) followed by 18 months of oral azathioprine was analyzed in 27 patients (20 female) with systemic sclerosis and worsening interstitial lung disease. Bérenzé and colleagues concluded that the therapeutic regimen was well tolerated and found that $51.8 \%$ of patients had stable disease or had improved after the 2-year treatment period.

Original article Bérenzé A et al. (2008) Therapeutic strategy combining intravenous cyclophosphamide followed by oral azathioprine to treat worsening interstitial lung disease associated with systemic sclerosis: a retrospective multicenter open-label study. J Rheumatol 35: 1064-1072

\section{SJÖGREN'S SYNDROME}

A mouse study has shown that mucosal administration of $\alpha$-fodrin can prevent progression of Sjögren's syndrome. Immunization with $\alpha$-fodrin was associated with decreased levels and delayed appearance of anti- $\alpha$-fodrin and anti-type 3 muscarinic acetylcholine receptor polypeptide antibodies, decreased appearance of antinuclear antibodies, decreased serum levels of interferon- $\gamma$, and increased number of Foxp $3^{+} \mathrm{CD} 4^{+} \mathrm{CD} 25^{+}$regulatory $\mathrm{T}$ cells. Administration of $\alpha$-fodrin was also associated with decreased lymphocytic infiltration and expression of $\alpha$-fodrin in the salivary glands of treated mice, as well as decreased fluid intake.

Original article He J et al. (2008) Mucosal administration of a-fodrin inhibits experimental Sjögren's syndrome autoimmunity. Arthritis Res Ther 10: R44

\section{BONE FORMATION}

Although animal-derived mesenchymal stem cells (MSCs) have been successfully used for tissue engineering in the treatment of large bone defects, human MSCs have not shown as much promise. A study of human MSCs, however, has shown that activation of protein kinase A stimulates robust bone formation through induction of genes such as ID2 and FOSB.

Original article Siddappa R et al. (2008) cAMP/PKA pathway activation in human mesenchymal stem cells in vitro results in robust bone formation in vivo. Proc Natl Acad Sci USA 105: 7281-7286 